\title{
Regionalização: um desafio para o planejamento estratégico do desenvolvimento ${ }^{1}$
}

Regionalization: a challenger to the development strategic planning

\author{
J osé Elmar Feger 2 \\ Augusto Fischer ${ }^{3}$ \\ Virginia Elisabeta Etges 4 \\ Adriana Marques Rossetto 5
}

\begin{abstract}
Resumo: O tema abordado no artigo discute os critérios de regionalização com vistas ao planejamento estratégico. O objetivo central é contribuir com subsídios para adensar o debate sobre o planejamento estratégico do desenvolvimento regional. Trata-se de um ensaio teórico, pois pretende aprofundar conhecimentos e trazer alguns aspectos importantes à compreensão do tema, especialmente quando se pretende mencionar estratégias de desenvolvimento; entretanto, utilizam-se dados de dois estudos empíricos para sustentar os pressupostos colocados. Uma questão orienta o debate: do ponto de vista da elaboração de estratégias, como deve ser delimitada a região de interesse? Ressalta-se que essa questão ainda precisa de mais estudo, a fim de ser respondida, porém é pressuposto quando se elaboram estratégias de desenvolvimento sustentável. Após a revisão bibliográfica e a análise de dados empíricos, conclui-se que a adoção de fronteiras fixas e definidas a priori na delimitação de regiões pode trazer limitações à elaboração de estratégias de desenvolvimento, principalmente porque dificulta apreender com maior propriedade a realidade.
\end{abstract}

Palavras-chave: Regionalização; Planejamento; Estratégia; Desenvolvimento.

\begin{abstract}
The theme approached in this article discusses the criteria for regionalization in order to the strategic planning. The central objective is to contribute to subsidies to increase debate about regional development strategic planning. That is an essay, because it intends to improve knowledge about important aspects of the theories to the theme comprehension, specially, when discussing development strategies, however, uses data from two empirical studies to support the assumptions placed. A question orients the debate: from the strategic view, how must be defined de interest region? Standing out that the question requires further study for the correct answer, however, that is a key when intends to prepare sustainable development strategies. After a bibliographic research and the empiric data analysis, it is concluded that the use of fixed frontiers and a priori defined to region delimitation they can bring limitations to the development strategies, especially because they make it difficult to learn the reality.
\end{abstract}

Key Words: Regionalization; Planning; Strategy; Development.

J EL: O18; R12

\footnotetext{
${ }^{1}$ Artigo recebido em julho de 2010 e aprovado em agosto de 2010.

2 Doutor em Desenvolvimento Regional pela Universidade de Santa Cruz - UNISC. Professor da Universidade Federal do Paraná - UFPR e pesquisador colaborador de grupos de pesquisa da Fundação Universidade do Oeste de Santa Catarina e da Fundação Universidade Regional de Blumenau. E-mail: joseelmar.feger@unoesc.edu.br

${ }^{3}$ Doutor em Administração; Professor e Pesquisador do Mestrado Profissional em Administração (em elaboração) da Universidade do Oeste de Santa Catarina-UNOESC, Campus de Joaçaba, E-mail: augusto.fischer@unoesc.edu.br

${ }^{4}$ Doutora em Geografia Humana. Professora e Coordenadora do Programa de Mestrado e Doutorado em Desenvolvimento Regional da Universidade de Santa Cruz do Sul. E-mail: etges@unisc.br

5 Doutora em Engenharia da Produção. Professora e Coordenadora do Programa de Mestrado em Gestão de Políticas Públicas da Universidade do Vale do Itajaí. E-mail: arossetto@univali.br
} 


\section{Introdução}

Nas últimas décadas, intensificaram-se as discussões sobre regionalização tanto no contexto da academia quanto da sociedade, mais especificamente na esfera pública. Assunto antes restrito ao âmbito da geografia, atualmente tem interessado à sociologia, saúde, urbanismo, economia. No campo da administração, como apontam Gil, Oliva e Silva (2007), ainda há um debate insipiente relativo às implicações regionais sobre seu objeto de estudo. Diante desse fato, esses autores instigam os administradores a ampliarem seus olhares para além de suas práticas correntes e das questões de sua especialidade, a fim de contribuir para a identificação de estratégias que viabilizem o desenvolvimento em diversos âmbitos.

Entretanto, mesmo que o assunto seja tratado de forma periférica na discussão sobre as aglomerações empresariais que emergiram nas últimas décadas de forma recorrente, a partir de estudos relacionados com clusters, arranjos produtivos e sistemas locais de produção (PORTER, 1990; CASAROTTO; PIRES, 2001; AMATO NETO, 2000, 2005; DI SERIO, 2007), todos implicam em recortes espaciais e, por conseguinte, envolvem algum tipo de regionalização. Na esfera pública, observam-se implicações dessa questão nas políticas de desenvolvimento territorial, tanto no Ministério da Integração Nacional com a Política Nacional de Desenvolvimento Regional (PNDR) (BRASIL, 2007) assim como no Ministério do Turismo com o Programa de Regionalização do Turismo - Roteiros do Brasil (BRASIL, 2004). Em alguns estados, surgem instituições regionais por iniciativa da sociedade ou do governo que visam promover o desenvolvimento, tais como, as Associações de Municípios, os Fóruns e Agências de Desenvolvimento, as Secretarias de Desenvolvimento Regional (SDRs) os Conselhos Regionais de Desenvolvimento (Coredes), implantados nos estados do Paraná, Santa Catarina e Rio Grande do Sul. Todas essas instituições e programas estão circunscritos em um determinado espaço e articulam ações conjuntas no sentido de alcançar o desenvolvimento sustentável.

Os pressupostos que os orientam, estão pautados nos conceitos de desenvolvimento endógeno discutidos por autores como Benko e Lipietz (1994), Amin (1998), Putnam (2002), Becker (2003). Estes autores assumem que o desenvolvimento ocorre a partir do engajamento dos atores locais com vistas a aproveitar os recursos disponíveis. Entendem os mesmos que, por meio de processos de planejamento participativo, é possível estabelecer estratégias mais consistentes e com isso empreender ações mais eficazes e sustentadas.

Diante desse contexto, uma questão merece ser discutida com maior ênfase caso a administração pretenda se inserir neste debate. Trata-se da delimitação da área de estudo ou de intervenção mediante o planejamento. O tema que se pretende abordar neste texto diz respeito, justamente, aos critérios de regionalização. O objetivo central é contribuir com subsídios para adensar o debate sobre o planejamento estratégico do desenvolvimento regional.

Como o próprio objetivo principal já indica, o artigo pode ser classificado como um ensaio, uma vez que pretende aprofundar conhecimentos e apresentar alguns aspectos teóricos importantes à compreensão do tema, especialmente quando se indicam estratégias de desenvolvimento. Todavia, não se propõe fazer um resgate intenso dos conceitos inerentes ao assunto, mas, a partir de alguns pressupostos e dados empíricos, levantar questionamentos, a fim de ampliar as reflexões sobre regionalização, muito bem iniciada, no campo da administração, por Gil, Oliva e Silva (2007). 
Uma questão que orienta o debate pode ser assim descrita: do ponto de vista da elaboração de estratégias, qual deve ser a região de interesse como área de abrangência? Ressalta-se que essa questão ainda precisa de mais estudos para ser respondida, porém é pressuposto à definição de estratégias de desenvolvimento sustentável, implicando reavaliação das concepções de planejamento estratégico do desenvolvimento regional, especialmente no que diz respeito à sua abrangência, ao envolvimento dos atores, à identificação das potencialidades locais, entre muitos outros aspectos.

A fim de organizar as ideias centrais que suportam a reflexão proposta, o artigo está dividido em cinco seções: a introdução apresenta o objetivo, que foi permitir ao leitor uma visão geral do assunto. A segunda seção apresenta alguns pressupostos teóricos que suportam a discussão, a qual foi organizada no sentido de estimular uma reflexão em relação às dificuldades para se delimitar áreas para planejamento. $\mathrm{Na}$ terceira seção, discutem-se os procedimentos metodológicos adotados para se obter e analisar os dados. Na quarta, apresentam-se dados empíricos, levantados a partir de fontes secundárias, os quais foram reunidos, com o fim de auxiliar na reflexão sobre regionalização e estratégia. Finalmente, na quinta e última seção, fazem-se as considerações finais.

\section{Planejamento Estratégico e Desenvolvimento Regional}

O desafio a ser enfrentado neste particular consiste na regionalização como delimitação à elaboração de planejamento estratégico. É clara a intenção do governo brasileiro em promover o desenvolvimento a partir de processos de planejamento participativo, ao se tomar por base os documentos disponibilizados pelos Ministérios da Integração Nacional e do Turismo. Uma breve discussão sobre o processo de planejamento estratégico, portanto, parece necessária.

Planejamento é um termo em voga na atualidade, cujo conceito evoluiu a partir do debate que se intensificou ao longo do século XX. Existem vários entendimentos sobre ele; entretanto, em essência, cada um deles trata de prever e desenvolver ações em direção a um futuro desejável diferente do atual, que implica uma dimensão temporal significativa (OLIVEIRA, 1999) e a busca pelo aprimoramento dos métodos adequados para alcançá-lo (HAMPTON, 1990).

A respeito do futuro, o planejamento contribui para atender a três tipos de necessidades a ele relacionadas: criar um futuro; enfrentar situações futuras conhecidas ou previsíveis; e/ ou coordenar eventos e recursos entre si. O impacto que esses acontecimentos almejados para o futuro exercem nas organizações depende das atitudes que os gestores possuem ao coordenar as ações, que podem ser: pró-ativas quando são desenvolvidas para impulsionar mudanças ou para criar capacitações para se adaptar a novas situações; e, reativas, constituindo apego ao conservadorismo e incapacidade de adaptação aos novos cenários, optando-se por se render às forças que desejam a estabilidade. A atitude dos planejadores, como também das pessoas e organizações afetadas pelo planejamento deve ser clara, não havendo uma ou outra de forma pura em virtude da necessária diversidade. À medida que a atitude pró-ativa encaminha ao crescimento e à mudança, a segunda impede mudanças abruptas ou desnecessárias, mantendo o equilíbrio (MAXIMIANO, 2000).

Quanto à estratégia, esta pode ser considerada como o conjunto de decisões fixadas em um plano ou que emerge do próprio processo organizacional, integrando missão, objetivos e sequência de ações administrativas em um todo interdependente 
(MOTTA, 1991). Para ele, estratégia pode ser tanto um guia a ser seguido, quando definida anteriormente (planejada), quanto o resultado dos comportamentos organizacionais definidos a posteriori. Já Simon (1971) define o termo como um conjunto de decisões que determinam o comportamento a ser exigido pelas pessoas ou organizações em um determinado período de tempo. Desvendar as diversas conotações que tomam os conceitos de estratégia, segundo Mintzberg e outros (2000), demandaria um esforço desmedido. Os referidos autores, a partir da análise dos conceitos defendidos por diversas escolas que se preocupam com o estudo da temática, apresentam cinco entendimentos possíveis para estratégia:

a) vista como uma direção ou guia de ação a ser seguido, a fim de se alcançar um futuro pretendido, constituindo um plano;

b) a manutenção de uma série de comportamentos, os quais se tornam consistentes ao longo do tempo, buscando-se a verificação de coerências no comportamento passado, no sentido de criar um modelo; nesse caso, é vista como um padrão;

c) concebida como o lugar escolhido para posicionar um determinado produto no mercado, englobando um conjunto de atividades que criam uma posição única e valiosa do produto, caracterizando-se como uma posição;

d) o meio pelo qual uma empresa executa as coisas, fixando o olhar tanto para dentro quanto para fora, em busca de alcançar uma visão ampla; nesse caso, é entendida como uma perspectiva;

e) como uma manobra destinada a confundir um concorrente, mais no sentido de um estratagema, e não como um desejo de realização da ação, vista como um pretexto.

Nota-se certa similaridade entre os conceitos de planejamento e estratégia, especialmente quando vista como um plano, posição ou perspectiva. Nesse caso, coaduna com o pensamento de Oliveira (1999), quando alega que o produto do planejamento estratégico consiste no direcionamento de esforços para um ponto comum, na consolidação do entendimento da missão, dos propósitos, das estratégias e das metas por todos os envolvidos com a organização, constituindo o estabelecimento de uma agenda de ações por um período de tempo. Nesse sentido, verifica-se que o conceito utilizado para nortear o planejamento do desenvolvimento regional é consoante com essa última noção. A título de exemplo, para o órgão oficial de turismo brasileiro, trata-se de um processo aplicado à atividade turística de um país, ou região, por intermédio do qual se diagnostica seu desenvolvimento e se fixa um modelo de atuação, mediante o estabelecimento de objetivos, metas e instrumentos visando impulsioná-la, coordená-la e integrá-la ao conjunto macroeconômico em que se insere (EMBRATUR, 1999). Esse conceito é compartilhado por estudiosos do turismo, por exemplo, Acerenza (1991), Petrocchi (2001), Beni (1998, 2006). Quando se trata do desenvolvimento de maneira mais ampla, nota-se, nas proposições de políticas públicas, como também nos processos desencadeados por instituições públicas ou privados, esse mesmo viés.

Sobre o desenvolvimento, entende-se que a confusão entre crescimento e desenvolvimento foi superada. A análise da literatura esclarece que os dois termos não são sinônimos, já que crescimento remete, quase que exclusivamente, à esfera econômica, excluindo-se aspectos fundamentais, como o ecológico, o ético e o político. A ética necessária ao desenvolvimento traduz-se em solidariedade sincrônica e solidariedade diacrônica que, combinadas, podem conduzir a um novo estilo de vida às populações (SACHS, 2002). Essa discussão tem permeado diversos estudos, em 
especial após a difusão do conceito de desenvolvimento sustentável e ampliado as agendas de desenvolvimento em todos os níveis de planejamento e gestão. Importantes pressupostos, nessa nova concepção de desenvolvimento, são: o entendimento sobre a necessidade de participação das comunidades envolvidas em todas as fases de planejamento e de gestão desse desenvolvimento e a crença de que a tarefa de promovê-lo não é exclusiva dos governos nacionais, mas que pode ser mais eficazmente conduzida por outros níveis de governo.

Além disso, está posto que o desenvolvimento é mais facilmente alcançado por meio de redes sociais que se configuram por uma articulação de esforços e ações com vistas a garantir a qualidade de vida das atuais e futuras gerações. Putnam (2002), ao relacionar o desempenho econômico e institucional das regiões italianas às suas tradições cívicas e às características da organização social, como confiança, normas e sistemas, ao que denominou capital social, argumentou que essa estrutura contribui para aumentar a eficiência da sociedade, facilitando as ações coordenadas necessárias ao desenvolvimento regional.

Finalmente, outro ponto convergente é o de que o desenvolvimento é um processo endógeno, isto é, depende da articulação de forças do próprio território, o que resulta em capacidade de dinamização socioeconômica e ambiental. Nesse sentido, a organização territorial/regional deixou de ter um papel passivo. Para Benko e Lipietz (1994), a importância atribuída aos fatores endógenos chega a caracterizar uma nova ortodoxia na disciplina alavancada. Por um lado, pelo interesse no sucesso de algumas regiões, como os distritos industriais da Terceira Itália; por outro, pela insatisfação com o resultado das políticas tradicionais de desenvolvimento regional. Esse processo de otimização das potencialidades locais e regionais não pode prescindir, no entanto, de considerar a inserção do local no contexto global. Sem esse cuidado, um ingênuo otimismo quanto às possibilidades locais diante da imposição de mecanismos dos mercados, externos ao território, mas determinantes no processo de seu desenvolvimento, pode direcionar ações equivocadas (BECKER, 2003).

Essa nova maneira de pensar o desenvolvimento coloca a região como um importante espaço de negociação e lócus das ações consideradas preponderantes ao processo. A região corresponde a uma área geográfica que constitui uma entidade que permite, simultaneamente, a descrição de fenômenos naturais e humanos, a análise de dados socioeconômicos e a aplicação de uma política. Funda-se em duas características principais: homogeneidade e integração funcional e resulta, ao mesmo tempo, em um sentimento de solidariedade vivida e em relações de interdependência com os restantes conjuntos regionais e com o espaço nacional e internacional (LAJ UGIE; LACOUR, 1979 apud BENKO, 1999).

Atualmente, com as facilidades de comunicação e de transporte, mediante o processo denominado globalização, ocorrem interferências constantes no seio das comunidades regionais. Nesse sentido, "[...] o espaço geográfico ganha novos contornos, novas características, novas definições. E, também, uma nova importância, porque a eficácia das ações está estreitamente relacionada com a sua localização" (SANTOS, 2000, p. 79).

Em uma reflexão sobre regiões e processo de regionalização, Limonad (2004, p. 58) recorda que, a despeito das adjetivações que acompanham a discussão de região como categoria de análise, ela é antes de qualquer coisa uma construção social que atende a interesses precisos. A autora destaca que a região "[...] constrói-se a partir da ação de distintos agentes em múltiplas escalas articuladas que de certa forma encontram um rebatimento em práticas e processos socioespaciais histórica e 
geograficamente localizados." Nesse sentido, uma regionalização fundamenta uma reflexão teórica ou atende a necessidades impostas por políticas setoriais, práticas de planejamento ou processos de desenvolvimento regional. Assim, as regionalizações possíveis para um determinado território podem apresentar variações em razão da finalidade a que se propõe atender. Essa forma de pensamento é consoante com a de Lacoste (1988), ao criticar o método utilizado pela geografia tradicional. O autor destaca que o método mais utilizado para realizar estudos científicos, e que se proliferou para outros fins, consiste em aprofundar conhecimentos sobre diversos aspectos que se mantém ao longo do tempo, excluindo das análises a evolução econômica e social recente.

Esse ato dos pesquisadores impede a apreensão mais eficaz das características espaciais dos diferentes fenômenos econômicos, sociais e políticos. "De fato, cada um deles tem uma configuração geográfica particular que não corresponde à da 'região.'” (LACOSTE, 1988, p. 62). Para compreendê-los com maior propriedade, é necessário levar em conta as linhas de força que estruturam o espaço, evitando que sejam ocultas distintas formas espaciais pelo modo de regionalização utilizada que recorta o espaço em proporções predefinidas e estáticas.

As críticas feitas pelo autor à forma de regionalização e percepção do espaço, que é disseminada pela mídia, demonstram que esse pensamento se torna um obstáculo ao conhecimento como instrumento de ação. Os fenômenos que podem ser isolados pelo pensamento não se ordenam espacialmente segundo grandes compartimentos, mas ao contrário, superpõem-se. Para Lacoste $(1988$, p. 68), o método mais eficaz que permite pensar estrategicamente a complexidade do espaço terrestre é fundamentado, em grande parte, na observação das intersecções dos múltiplos conjuntos espaciais (para o autor, conjunto espacial é considerado como uma forma de destacar na carta o contorno, ou seja, os limites dos diversos conjuntos levados em consideração) que se podem formar e isolar pelo raciocínio e pela observação de suas configurações cartográficas.

A ampliação deste debate tem gerado propostas diferenciadas para a definição dessas regiões para enfoques de planejamento e de desenvolvimento. Paiva (2004), ao levantar questões como as dificuldades de planejamento sem uma definição criteriosa dos limites em que ele deve ocorrer, além de considerar que os dados acumulados possam esconder a heterogeneidade interna à área definida para planejamento, argumenta que os critérios políticos adotados para a delimitação de áreas de planejamento implicam restrições, visto que circunscrevem as análises e decisões em fronteiras intransponíveis, na visão tradicional, deixando de levar em conta a integração dos agentes inscritos no território, especialmente as relações de troca entre os atores envolvidos na localidade. Ao questionar essas delimitações feitas a priori, apresenta uma metodologia de identificação do potencial endógeno de territórios, elemento que demarcaria uma região para fins específicos de planejamento. $\mathrm{O}$ autor reconhece a complexidade que envolve a questão; por isso, sugere que devem ocorrer, pelo menos, dois momentos: um primeiro, no qual se realiza um diagnóstico preliminar das potencialidades regionais com base em dados secundários; um segundo, que demanda pesquisa de campo, com levantamento de dados primários, a fim de testar a consistência e a possibilidade econômica das hipóteses surgidas no diagnóstico preliminar.

A partir da revisão teórica, até aqui realizada, entende-se que o processo de regionalização envolve uma infinidade de elementos físicos e suas relações com atores locais e externos. Ao concordar que o desenvolvimento é o resultado de um processo de interação e interdependência entre objetos e pessoas, que se inscreve no 
território, a partir da percepção e ação dos agentes (BOISIER, 2003), aceita-se, inclusive, que a região é formada por diversos conjuntos que se sobrepõem, interconectam-se e não são necessariamente ocupantes de um único espaço com contornos iguais (LACOSTE, 1988). Nesse sentido, um estudo regional deveria partir do mapeamento dos elementos localizados no espaço terrestre e, a partir das interrelações entre estes, verificar os conjuntos que se formam, bem como suas conexões.

A esse respeito, uma proposição aceita é a de que as regiões são construídas a partir das ações de agentes em múltiplas escalas que se encontram espacialmente localizadas. Uma regionalização deve, dessa maneira, fundamentar-se em uma reflexão teórica ou atender a necessidades impostas por políticas ou práticas de planejamento regional. Nesse sentido, as regionalizações possíveis em um determinado território podem apresentar variações, dependendo das finalidades que pretendem atender (LIMONAD, 2004). Um método que, segundo Lacoste (1988), se prolifera, consiste em aprofundar conhecimentos sobre os diversos aspectos que se mantêm ao longo do tempo, excluindo das análises a evolução recente. Essa maneira de pensar acaba se tornando um obstáculo ao conhecimento como instrumento de ação, pois, parte de uma regionalização preexistente, sem o questionamento sobre sua validade para os interesses das políticas ou programas. O método que permitiria pensar com maior eficácia estratégias, evitando-se aspectos que podem representar obstáculos à ação que se pretende empreender, precisa levar em consideração as diversas intersecções entre as configurações que se formam no espaço.

\section{Procedimentos Metodológicos}

O interesse pela discussão e conhecimento de métodos de elaboração de estratégias ao desenvolvimento regional tem instigado os autores deste artigo a encontrar alternativas viáveis para que o planejamento seja coerente com a realidade. $\mathrm{Na}$ caminhada em busca de respostas, foram realizadas incursões nos conhecimentos sobre métodos de planejamento estratégico empresarial e sua adaptação ao desenvolvimento regional. Constatou-se que os preceitos teóricos, embora importantes, não eram suficientes para dar conta da empreitada pretendida. Ao tomar conhecimento sobre o debate que ocorre na geografia relacionada ao território e à regionalização, verificou-se que um possível entrave, o qual poderia dificultar o planejamento estratégico, é justamente a pouca atenção atribuída à definição da região objeto de análise. Em vista disso, alguns estudos exploratórios foram realizados, a fim de melhor compreender o processo de regionalização. O presente artigo consiste em uma síntese dos conteúdos analisados e na apresentação de dados preliminares, os quais permitem uma melhor compreensão do tema.

Por constituir uma primeira incursão sobre os dados, considera-se o estudo exploratório, uma vez que tem como finalidade conhecer as implicações que os pressupostos teóricos trazem ao campo do planejamento regional, utilizando-se de casos ilustrativos para permitir a compreensão do tema com maior profundidade (GIL, 2002). O estudo pode ser classificado ainda como descritivo, pois, segundo Triviños (1987), busca descrever os fatos e fenômenos de determinada realidade. Pesquisas dessa natureza estudam e descrevem as características, propriedades ou relações existentes em uma comunidade, grupo ou em uma realidade pesquisada. Assim como no estudo exploratório, o estudo descritivo favorece, em uma pesquisa mais ampla e completa, as tarefas de formulação clara do problema e da hipótese como tentativa de solução (TRIVIÑOS, 1987; CERVO; BERVIAN, 1983). Em vista 
disso, o estudo não pretende apresentar conclusões definitivas, e sim levantar questões e hipóteses que podem orientar novas pesquisas (GIL, 2002).

Quanto à abordagem, o estudo caracteriza-se como qualitativo, visto que, para alcançar os objetivos propostos, há necessidade de uma descrição detalhada e análise da interação e o comportamento dos agentes no território (ALVEZ-MAZZOTTI; GEWANDSZNAJ DER, 2001). Pode-se, inclusive, justificar o enquadramento da pesquisa como qualitativa, embora se utilizem, em alguns momentos, dados quantitativos, pois a pretensão é compreender e explicar um fenômeno social, no caso a delimitação de regiões como área de planejamento, e não a sua frequência (GODOY, 1995).

No que se refere à delimitação temporal, o estudo teve um corte transversal, visto que se concentrou no período corrente. Quanto às fontes utilizadas, a pesquisa caracteriza-se como bibliográfica e documental, uma vez que os dados colhidos para análise são originários de fontes secundárias e literatura existente sobre a temática. A discussão proposta envolve duas situações: a primeira consiste na regionalização do turismo; a segunda, à regionalização da produção de móveis com predominância em madeira. A delimitação espacial, portanto, corresponde à tradicional, ou seja, referese a regiões previamente existentes, a fim de verificar empiricamente os impactos que os pressupostos teóricos relacionados à regionalização podem trazer ao planejamento.

Para a discussão sobre a regionalização do turismo, buscaram-se dados disponíveis no Ministério do Turismo. Optou-se por tomar duas regiões próximas, definidas a priori, a fim de observar a aplicação dos conceitos discutidos por Lacoste (1988). As regiões escolhidas foram a região do Vale do Contestado em Santa Catarina e a de Hidrominerais no estado do Rio Grande do Sul. Após a identificação dos municípios que compunham essas regiões, foram coletados dados nos sites das instituições responsáveis pelo turismo nos dois estados, a fim de verificar a presença de atrativos turísticos e meios de hospedagem existentes nas áreas previamente definidas. Quanto ao turismo, o que evidencia a existência de um elemento turístico em uma determinada área é a presença do turista (BOULLÓN, 2002). Esses dados foram classificados por município pertencente a cada região. Após o levantamento e análise dos dados, estes foram alocados em um mapa por meio do software terraview, para permitir a disposição espacial dos elementos pesquisados, com o propósito de verificar a espacialização do turismo, método utilizado por Boullón (2002).

O segundo processo de regionalização consistiu na análise de uma atividade produtiva, a industrialização de móveis com predominância em madeira. Para a escolha da atividade, levou-se em conta o defendido por Paiva (2004), para o qual é importante identificar nos municípios ou regiões uma atividade que sirva de suporte ao desenvolvimento, indicando como ponto de partida o Quociente Locacional (QL) (trata-se de um indicador utilizado na economia para identificar a concentração de determinadas atividades em um território; para maiores detalhes, veja-se Paiva (2004) para uma análise preliminar). No presente estudo, calculou-se o QL para verificar a concentração da atividade industrial de móveis com predominância em madeira nos municípios pertencentes a três Conselhos Regionais de Desenvolvimento (Coredes) existentes no estado do Rio Grande do Sul (Hortênsias, Vale do Caí, Serra). Da mesma forma que, para a análise da regionalização do turismo a escolha dos Coredes foi aleatória, o único critério adotado é que fossem vizinhos um do outro, a fim de permitir a análise dos dados e extrapolar os limites regionais. Ressalta-se que, nesse caso, as áreas foram tradicionalmente delimitadas para fins de articulação 
política e promoção do desenvolvimento. Os dados para calcular os QLs foram obtidos no Relatório Anual de Informações Sociais (RAIS), o qual informa o número de empresas e o respectivo número de empregados. Com base nesses dados, calculouse a concentração de empresas para todos os municípios das três regiões, os quais foram também alocados em um mapa, mediante o software terraview, a fim de analisar a conformação espacial.

A análise dos dados levou em consideração a discussão feita por Lacoste (1988) e Limonad (2004), os quais argumentam que as regionalizações devem ser orientadas pelos interesses dos planejadores e pesquisadores, podendo em um mesmo espaço coexistirem diversas regionalizações.

\section{Aspectos Limitantes ao Planejamento do Desenvolvimento}

Com base nos pressupostos discutidos na seção anterior, foram reunidos alguns dados na tentativa de operacionalizar os conceitos. Ressalta-se que se trata de dados secundários, levantados unicamente com o propósito de exemplificar as implicações que uma visão limitada do contexto pode trazer ao planejamento estratégico. Primeiramente, será abordada a regionalização do turismo e, na sequência, a regionalização com base no setor moveleiro.

Está em curso no país o Programa de Regionalização do Turismo, como parte das Políticas Nacionais para o setor. Analisando-se os pressupostos que orientam tal programa, verifica-se que coadunam com os de desenvolvimento endógeno sustentável. Por meio de oficinas de planejamento e de definições de estratégias para a implementação do Programa de Regionalização do Turismo, realizadas nos estados, foram identificadas 219 regiões turísticas no país com as necessidades e potencialidades de cada uma delas (Essas regiões foram depois atualizadas em 2005, resultando em 200, abrangendo 3.819 municípios). A partir das referidas oficinas, com a participação dos governos estaduais, iniciativa privada, organizações não governamentais, foram obtidos os subsídios para as diretrizes operacionais do programa (BRASIL, 2004).

Beni (2006), ao realizar uma análise da evolução das políticas públicas para o turismo no Brasil, assevera que corresponde a uma das melhores propostas já feitas ao turismo no país; entretanto, a partir dos pressupostos já discutidos, não é eficazmente implementada. Ao se analisar o mapa disponível no site do Ministério do Turismo, que trata da regionalização do turismo em 2006, alguns aspectos podem ser observados.

O primeiro é que as regiões Norte e Nordeste apresentam regionalizações turísticas mais dispersas, verificando-se grande quantidade de municípios não inseridos em nenhuma região turística. Nas regiões Centro-Oeste, Sudeste e Sul, basicamente não se observam municípios excluídos de regiões turísticas, exceto no estado do Rio Grande do Sul.

O segundo é que, apesar da indicação nas diretrizes políticas para o desenvolvimento do turismo explicitar que a regionalização deve se desviar das tradicionais regionalizações político-administrativas, não se verifica nenhuma região que venha abranger dois estados. Cada estado procedeu a sua regionalização, independentemente de haver ou não proximidade entre municípios turísticos no estado vizinho, mesmo com a indicação clara da existência de ligação entre destinos turísticos, como é o caso do passeio de Maria Fumaça entre Marcelino Ramos (RS) e 
Piratuba (SC), o qual aparece como atividade oferecida ao turista na divulgação dos dois municípios.

O terceiro diz respeito à existência de atrativos turísticos, efetivos ou potenciais, nos municípios integrantes de cada região turística. Esse fator parece não ter sido levado em consideração, pois, em pesquisa exploratória, tanto no site de divulgação da Secretaria de Turismo do Estado do Rio Grande do Sul (Setur) quanto no da Santa Catarina Turismo (Santur), verificou-se que, em torno de 30\% dos municípios indicados como pertencentes à Região Hidrominerais (RS) e Vale do Contestado (SC) não apresentam nenhum atrativo natural ou histórico-cultural. Em Santa Catarina, determinaram-se como regiões turísticas: Grande Oeste catarinense; Vale do Contestado; Serra catarinense; Caminho dos Príncipes; Vale Europeu; Rota do Sol; Grande Florianópolis; Encantos do Sul catarinense e Caminho dos Canyons. Já no estado do Rio Grande do Sul, as regiões são: Grande Porto Alegre; Litoral Norte gaúcho; Serra gaúcha; Hidrominerais; Missões; Pampa gaúcho; Central; Vales e Costa Doce.

Em uma incursão preliminar, a fim de ter uma noção do atual estágio de organização do turismo nas regiões, especialmente colher informações a serem utilizadas para subsidiarem este debate, pesquisaram-se no sitio de divulgação da Santur informações sobre a região do Vale do Contestado. Verificou-se que a região é composta por 62 municípios. Na sua área de abrangência, observa-se a existência de 97 atrativos naturais, 80 atrativos históricos e 171 caracterizados como outros, pois envolvem uma infinidade de atividades de interesse turístico, como parques de eventos, eventos realizados ao longo do ano, grupos folclóricos, artesanato, entre outros. Quanto ao número de meios de hospedagem, incluindo campings, pousadas e hotéis, constatou-se a existência de 135 estabelecimentos. No que concerne à alimentação (bares, restaurantes, churrascarias), constavam nos documentos disponibilizados na internet 286 empresas. Como já referido anteriormente, os atrativos turísticos estão concentrados somente em alguns municípios. Os que mais se destacam são: Caçador, Concórdia, Curitibanos, Fraiburgo, Irani, Porto União, Treze Tílias e Videira. Quando no seu sítio a Santur (2007) destaca os destinos e roteiros da região, destaca como municípios turísticos: Treze Tílias, Fraiburgo, Piratuba, Videira, Tangará, Pinheiro Preto, Porto União, Caçador, Irani, Itá, Seara e Frei Rogério. O principal atrativo da região, segundo a Santur, é a sua multiplicidade de "paisagens, de gentes e culturas. A Rota da Amizade [...] oferece a melhor infraestrutura hoteleira e gastronômica." Também, há destaque para o município de Treze Tílias, chamando atenção para a cultura austríaca e a arquitetura típica tirolesa. Quanto ao Vale da Uva e do Vinho, composto pelos municípios de Videira, Tangará e Pinheiro Preto, destacam-se a arquitetura típica diferenciada e a produção de vinho, por ser uma área com maior densidade de descendentes de italianos. A produção de maçã é evidenciada como atração de Fraiburgo. Piratuba é apresentada como a principal estância de águas termominerais da região (SANTUR, 2007).

A região denominada Hidrominerais, localizada no estado do Rio Grande do Sul, que faz limites com a do Vale do Contestado, situada em Santa Catarina, é composta por 46 municípios, com 50 atrativos naturais, 51 históricos e 29 caracterizados como outros. O número de hotéis existentes na sua área de abrangência corresponde a 72 unidades; os meios de alimentação compreendem 240 estabelecimentos. Da mesma forma que o observado na região Vale do Contestado, a existência de atrativos turísticos concentra-se em somente alguns municípios da região. São eles: Caiçara, Frederico Westphalen, Iraí, Aratiba, Entre Rios do Sul, Erechim e Marcelino Ramos. No sitio da Setur, a região é destacada como localizada 
junto a belas paisagens, em meio à mata nativa e estâncias hidrominerais. Como oportunidade de atividades para os visitantes, sugere a existência de grande número de trilhas e possibilidade de cavalgadas. Destaca, também, a produção de pedras preciosas, o artesanato em vime, cipó e madeira, além da pesca no Rio Uruguai (SETUR, 2007). No que diz respeito a essa região, ela está dividida em três microrregiões: Microrregião Águas e Pedras Preciosas, Microrregião Termas e Lagos e Microrregião Cultura e Tradição.

Nota-se que, quando se trata da comercialização de produtos turísticos, em grande parte, os municípios divulgados coincidem com os que apresentam maior número de atrativos. Como não há definição de como foi tratada a regionalização do turismo, há necessidade de verificar que critérios foram utilizados para inserir os demais municípios na região turística.

Para maior clareza dessa discussão, apresenta-se no Mapa 1 a demarcação das regiões turísticas previamente delimitadas para fins de atender às premissas demandadas pela Política Nacional de Turismo. Verifica-se no estado de Santa Catarina a demarcação da região denominada Vale do Contestado (vermelho). No estado do Rio Grande do Sul está demarcada a região denominada Hidrominerais, dividida em suas sub-regiões (laranja, marrom e azul). Em preto, aparecem os municípios que possuem maior número de atrativos turísticos que, segundo Boullón (2002), caracterizam-se como turísticos. Nesse sentido, observam-se algumas manchas espalhadas ao longo dos territórios estudados. Pode-se verificar que alguns conjuntos de municípios turísticos perpassam as divisas dos dois estados, como é o caso de Marcelino Ramos (RS) e Piratuba (SC).

Mapa 1 - Regiões Hidrominerais (RS) e Vale do Contestado (SC), destacando-se municípios turísticos

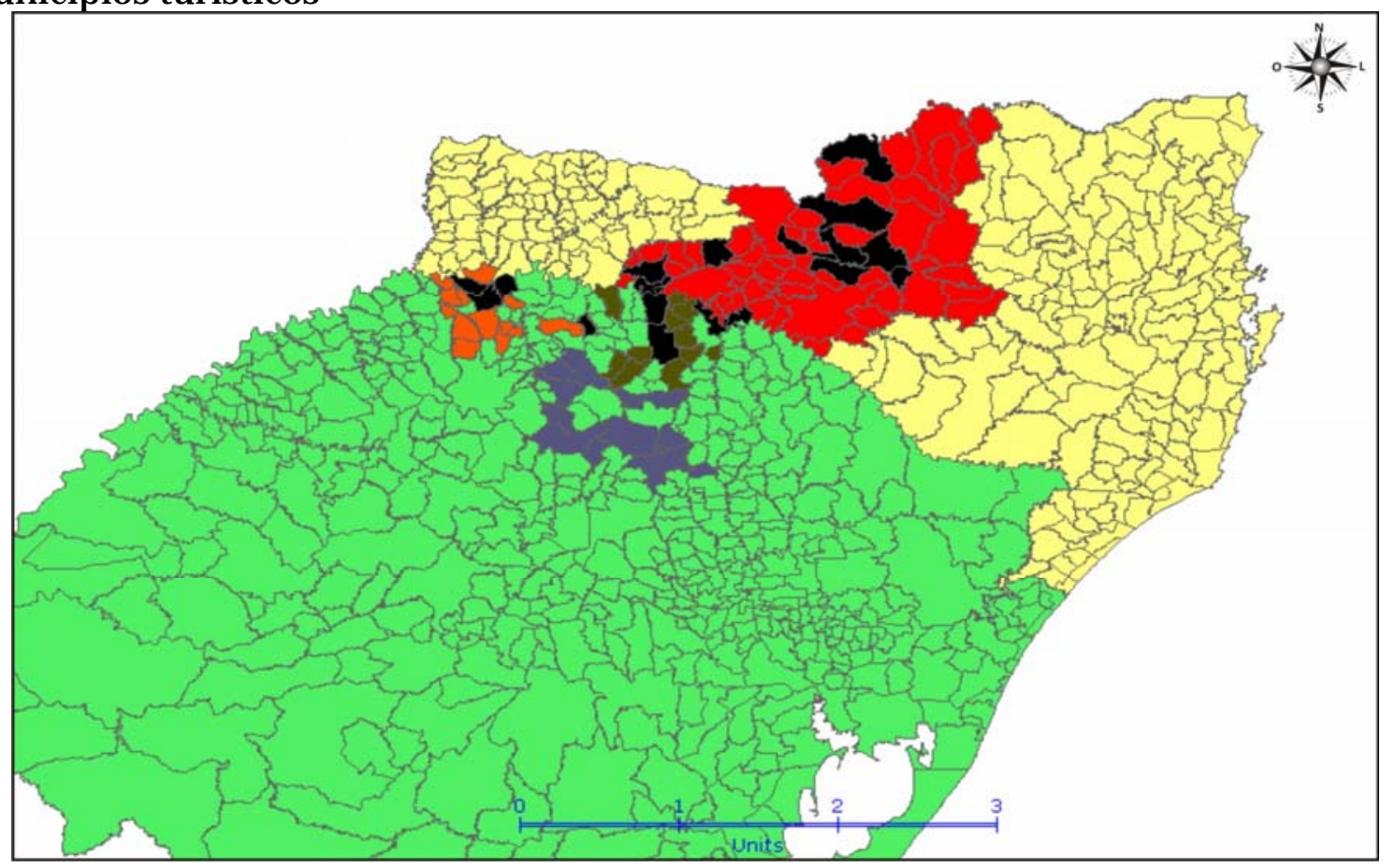

Fonte: os autores.

Ressalta-se que esse foi um levantamento exploratório, utilizando-se dados disponibilizados pelos órgãos oficiais de turismo dos dois estados e apenas para duas regiões do país. É necessário um estudo mais aprofundado, a fim de se obter 
conclusões mais precisas. Todavia, permite interrogar, aceitando-se que, para ser reconhecido como turístico, um território prescinde de atrativos turísticos em número e hierarquia suficientes para atrair determinado fluxo de visitantes (RUSCHMANN, 1999; PETROCCHI, 2001), e que esses atrativos se encontrem dispersos no espaço e sua possibilidade de integração dependa da proximidade e facilidade de deslocamento entre eles (BOULLÓN 2002). Pergunta-se: com base no conteúdo apresentado, essas regiões são efetivamente turísticas? É possível elaborar o planejamento estratégico do turismo de forma isolada, para a região Vale do Contestado (SC) e Hidrominerais (RS), sabendo-se que possuem atrativos próximos e até uma interligação através de ferrovia, com passeio de trem já consolidado entre dois municípios (Piratuba - SC e Marcelino Ramos - RS)?

Para ampliar essa discussão, a própria criação de instituições representativas para organizarem o processo de desenvolvimento (associações de municípios, Coredes, SDRs), quer por iniciativa do Estado, quer pela sociedade civil, constitui um avanço no sentido de superar limites; todavia, parece construir novo paradigma, pois os dados são organizados e analisados em novos compartimentos, sem levar em conta a distribuição espacial das atividades. Nesse sentido, essa forma de organização pode dificultar a compreensão da realidade, o que reduz a eficácia das estratégias de desenvolvimento.

Para a análise da atividade moveleira, utilizou-se o que Paiva (2004) sugere como ponto de partida viável para se discutir o desenvolvimento regional, a verificação das potencialidades existentes no território. Como método de análise, indica o cálculo do QL, uma medida que permite identificar a concentração de atividades em um determinado espaço. Em vista disso, foram traçados alguns dados de outras pesquisas exploratórias em andamento, que, todavia, podem dar suporte à argumentação efetuada.

Analisando-se os dados sobre o setor de móveis das áreas de abrangência dos Coredes Hortênsias, Vale do Caí e Serra, localizados no estado do Rio Grande do Sul, verifica-se que, no Corede Hortências, há concentração em apenas quatro municípios próximos: Canela, Gramado, Nova Petrópolis e Picada Café. Nesse sentido, caracteriza-se como atividade potencialmente importante à região; todavia, não se distribui igualmente por todo o espaço regional, constituindo um ponto essencial na análise, já apontado por Paiva (2004), pois, à medida que se dissecam os dados no interior da região, percebe-se sua heterogeneidade.

Outro aspecto observado é que, na região correspondente ao Corede Vale do Caí, os dados sobre a atividade sugerem que não seria uma potencialidade importante à região. Todavia, observa-se que é uma atividade que ocorre em, praticamente, todos os municípios da região, embora com expressão pequena, mas próxima dos municípios de Gramado, Canela e Nova Petrópolis, localizados no Corede Hortência. Estendendo-se o olhar para o Corede Serra, verifica-se que vários municípios próximos à fronteira com os Coredes Hortências e Vale do Caí, como Farroupilha, Bento Gonçalves e Garibaldi, possuem considerável atividade no setor.

Para melhor visualização, no Mapa 2 apresenta-se a localização dos municípios que possuem a atividade moveleira como representativa. Também, nesse caso, verifica-se a extrapolação das áreas das três regionalizações previamente delimitadas, os Coredes. 
Mapa 2 - Coredes Hortênsias, Vale do Caí e Serra, com destaque aos municípios que possuem predominância da atividade moveleira com base em madeira

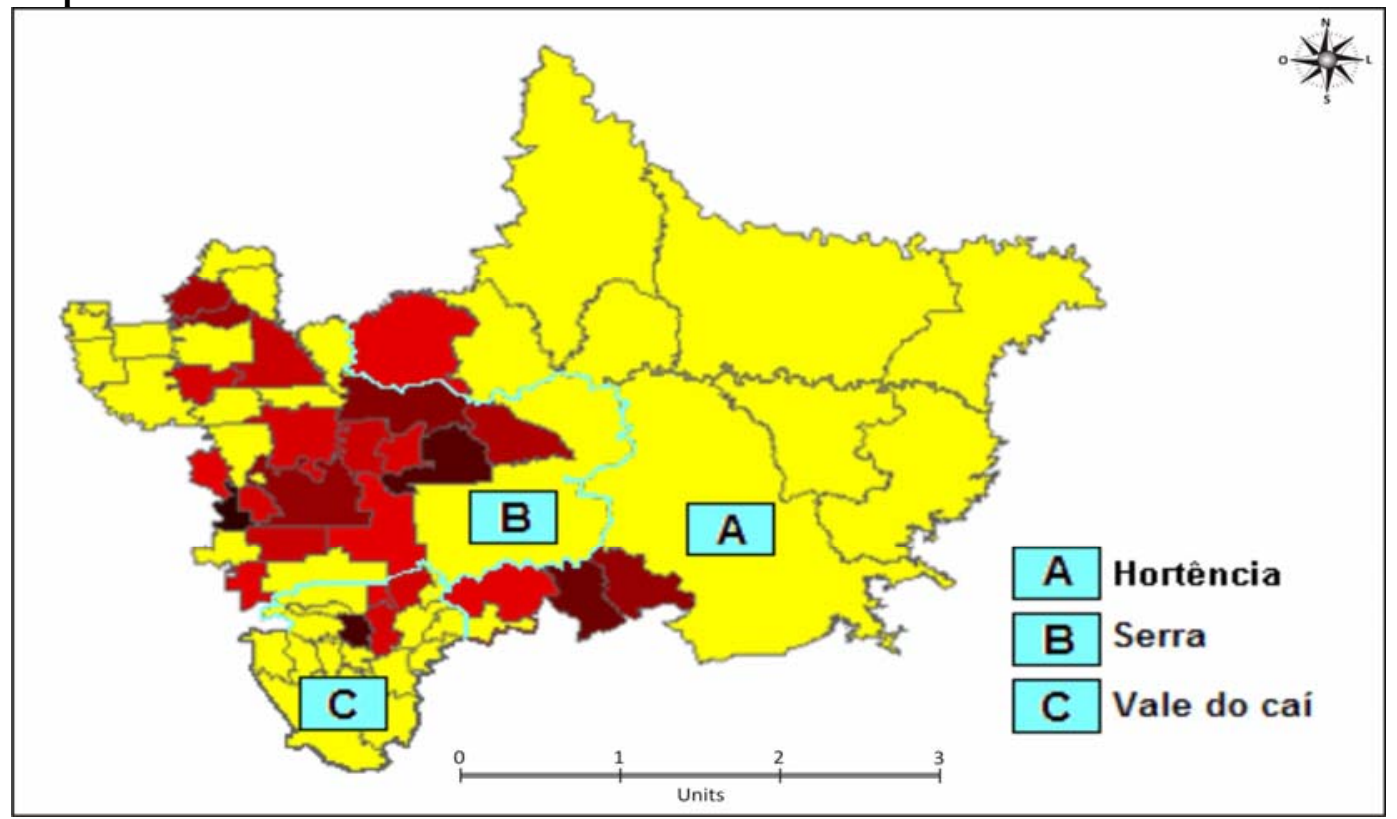

Fonte: os autores.

Algumas hipóteses emergem: a primeira é que, se considerar a atividade somente no território de circunscrição do Corede Hortências consolidado, corre-se o risco de elaborar estratégias ao incentivo da indústria moveleira, porém não é uma atividade que ocorre em todo esse território. A segunda é que talvez não se desenvolvam estratégias ao incentivo dessa produção no Vale do Caí, porque é pouco representativa, analisando-se os dados consolidados desse Corede. A terceira, que provavelmente ocorreria, dada a visão de que o planejamento deve ser circunscrito ao território previamente delimitado, haveria dificuldades em se pensar estratégias conjuntas para os três Coredes (Hortências, Vale do Caí e Serra) para incentivar essa atividade, mesmo ocorrendo em municípios próximos de suas fronteiras, pois os dados, como são atualmente coletados, não permitiriam essa percepção, mesmo sendo um processo de planejamento participativo.

Caso o pensamento dos autores arrolados para subsidiar este artigo seja correto, e se for aceita a hipótese de que as regiões não são homogêneas, e sim uma sobreposição de conjuntos que se formam a partir da articulação e interação de diversos agentes em um determinado espaço, e sua análise e delimitação levarem em conta os interesses dos pesquisadores e/ ou planejadores, consequentemente não correspondem a regionalizações definidas a priori. Diante do exposto, emergem algumas questões: como delimitar o espaço geográfico, a fim de se elaborar o planejamento estratégico para o desenvolvimento? Há possibilidade de se pensar em um planejamento estratégico único a cada região? Alguns setores deveriam ter estratégias elaboradas em conjunto por várias regiões?

Quando se inicia um processo de operacionalização dos conceitos para uma pesquisa e, mediante a exploração dos dados, amplia-se o campo de visão, chega-se a algumas encruzilhadas, as quais parecem, às vezes, intransponíveis. Todavia, o avanço do conhecimento parece emergir justamente dessas indagações. Os dados apresentados, como já intensamente referido neste texto, não pretendem defender uma tese, apenas servir de subsídios para a reflexão e discussão sobre o planejamento estratégico regional. Nesse sentido, trazem várias interrogações que podem orientar 
trabalhos de pesquisa específicos e que venham a adensar o conhecimento nesse tema.

\section{Considerações Finais}

$\mathrm{O}$ artigo surgiu de alguns estudos preliminares sobre o desenvolvimento regional e trouxe, à medida que os conhecimentos sobre o tema se aprofundaram, a percepção sobre sua complexidade. Nesse sentido, o desafio feito por Gil, Oliva e Silva (2007), os quais trazem uma brilhante descrição das diversas acepções de região, tornando o conceito extremamente abrangente, coloca a premissa de que ignorar os pontos de vista apontados pode limitar a elaboração de estratégias de desenvolvimento de forma mais eficaz.

Como o objetivo do artigo foi trazer alguns indícios para discussão sobre a regionalização com vistas ao planejamento estratégico, inicia-se com o pressuposto de que há limitações no modo de coleta e análise dos dados atualmente utilizados. Isso foi detectado nos dois casos pesquisados.

Foi possível verificar a concentração espacial da atividade moveleira nos Coredes, observando-se que é uma atividade que se concentra em uma faixa do território e que se desloca por intermédio dos seus limites. Alguns municípios apresentam maior concentração de empresas e podem ser observadas algumas aglomerações em torno destes, por exemplo, Gramado, Canela e Nova Petrópolis. Quanto ao turismo, analisando-se os dados, esse mesmo efeito é observado. Os atrativos turísticos concentram-se em alguns municípios próximos e em alguns casos ultrapassam os limites estaduais.

Considerando que o Planejamento Estratégico pressupõe ações concertadas, com objetivos predeterminados em um espaço territorial, no qual todos os agentes do desenvolvimento tenham forte sentimento de pertencimento ao processo, infere-se que a adoção de fronteiras fixas e definidas a priori pode trazer sérias consequências à elaboração de estratégias que direcionem ao desenvolvimento, principalmente porque dificultam apreender com maior propriedade a realidade.

Como alternativa às fronteiras fixas, para os dois casos analisados neste trabalho, sugere-se desenvolver e adotar um planejamento estratégico baseado nos objetos, no caso, o turismo e a indústria de móveis, considerando-se dimensões específicas como propõe Lacoste (1988). Pode se definir regiões diversas àquelas regiões geográficas existentes, por intermédio da aplicação da metodologia de cálculo dos quocientes locacionais (QLs) das concentrações de atividades conforme sugerido por Paiva (2004).

É preciso reconhecer as limitações do trabalho, uma vez que se trata de um estudo exploratório; contudo, são apontados alguns aspectos que precisam ser amplamente discutidos, a fim de ampliar os conhecimentos sobre o tema, especialmente no sentido de desenvolver metodologias apropriadas a uma adequada compreensão da realidade e orientar uma regionalização mais propícia ao planejamento estratégico regional. Nesse caso, um caminho possível poderia ser uma abordagem sistêmica. 


\section{Referências}

ACERENZA, M. Á. Administración del turismo: conceptualización y organización. México: Trillas, 1991.

ALVEZ-MAZZOTI, A. J.; GEWANDSZNAJOER, F. O método nas ciências naturais e sociais: pesquisa quantitativa e qualitativa. São Paulo: Pioneira, 2001.

AMATO NETO, J . Redes de Cooperação Produtiva e Clusters Regionais: oportunidades para as pequenas e médias empresas. São Paulo: Atlas, 2000.

AMATO NETO, J . (Org.). Redes entre organizações: domínio do conhecimento e da eficácia operacional. São Paulo: Atlas, 2005.

AMIN, A. An Institutionalist Perpective on Regional Economic Development. London: Department of Geography, UCL, 1998. Disponível em: <www.econgeog.org.uk/pdfs/amin.pdf>. Acesso em: 15 set. 2004.

BECKER, D. F. A Contradição em Processo: o local e o global na dinâmica do desenvolvimento regional. In: BECKER, D. F.; WITTMANN, M. L. (Org.). Desenvolvimento Regional. Abordagens Interdisciplinares. Santa Cruz do Sul: Edunisc, 2003.

BENI, M. C. Análise estrutural do turismo. São Paulo: Senac, 1998. $\overline{2} \overline{0} \overline{0} \overline{6}$ . Política e Planejamento de Turismo no Brasil. São Paulo: Aleph,

BENKO, G. A ciência regional. Oeiras: Celta, 1999.

BENKO, G.; LIPIETZ, A. As regiões Ganhadoras: Distritos e Redes, os Novos Paradigmas da Geografia Econômica. Oeiras: Celta, 1994.

BOISIER, S. Y si el desarollo fuese uma emergencia sistemica? Redes, Santa Cruz do Sul, v. 8, n. 1, p. 1-9, jan./ abr. 2003.

BOULLÓN, R. C. Planejamento do Espaço Turístico. Bauru: Edusc, 2002.

BRASIL. Política Nacional de Desenvolvimento Regional (PNDR). Brasília, DF: Ministério da Integração Nacional, 2007.

- Programa de Regionalização do Turismo: Roteiros do Brasil: Diretrizes Operacionais. Brasília, DF: Ministério do Turismo, 2004.

CASAROTTO FILHO, N.; PIRES, L. H. Redes de pequenas e médias empresas e desenvolvimento regional. São Paulo: Atlas, 2001.

CERVO, A. L.; BERVIAN, P. A. Metodologia científica: para uso dos estudantes universitários. 3. ed. São Paulo: McGraw-Hill do Brasil, 1983. 
DI SERIO, L. C. (Org.). Clusters empresariais no Brasil: casos selecionados. São Paulo: Saraiva, 2007.

EMBRATUR. Estudos do Turismo Brasileiro. Brasília, DF: Embratur, 1999.

GIL, A. C. Como elaborar projetos de pesquisa. 4. ed. São Paulo: Atlas, 2002.

GIL, A. C.; OLIVA, E. de C.; SILVA, E. C. Desenvolvimento da regionalidade: novo campo da administração. In: ENANPAD, 31., 2007, Rio de J aneiro. Anais... Rio de Janeiro: Anpad, 2007.

GODOY, A. S. Pesquisa qualitativa: tipos fundamentais. RAE, São Paulo, v. 35, n. 3, p. 20-29, maio/jun. 1995.

HAMPTON, D. R. Administração - comportamento organizacional. São Paulo: McGraw-Hill, 1990.

LACOSTE, Y. A geografia - isso serve em primeiro lugar, para fazer a guerra. Campinas: Papirus, 1988.

LIMONAD, E. Brasil século XXI, regionalizar para que? Para quem? In: LIMONAD, E. et al. Brasil século XXI - por uma nova regionalização? São Paulo: Max Limonad, 2004.

MAXIMIANO, A. C. A. Introdução à Administração. São Paulo: Atlas, 2000.

MINTZBERG, H.; AHLSTRAND, B.; LAMPEL, J . Safári de estratégia: um roteiro pela selva do planejamento estratégico. Porto Alegre: Bookman, 2000.

MOTTA, P. R. Gestão contemporânea: a ciência e a arte de ser dirigente. Rio de Janeiro: Record, 1991.

OLIVEIRA, D. P. R. Planejamento estratégico - conceitos, metodologia e práticas. São Paulo: Atlas, 1999.

PAIVA, C. A. Como identificar e mobilizar o potencial de desenvolvimento endógeno de uma região? Porto Alegre: FEE, 2004.

PETROCCHI, M. Gestão de pólos turísticos. São Paulo: Futura, 2001.

PORTER, M. E. Vantagem competitiva: criando e sustentando um desempenho superior. Rio de J aneiro: Campus, 1990.

PUTNAM, R. D.; LEONARDI, R.; NANETTI, R. Y. Comunidade e Democracia: a Experiência da Itália Moderna. 3. ed. Rio de J aneiro: Ed. FGV, 2002.

RUSCHMANN, D. Turismo e planejamento sustentável: a proteção do meio ambiente. São Paulo: Papirus, 1999.

SACHS, I. Caminhos para o Desenvolvimento Sustentável. Rio de J aneiro: Garamond, 2002. 
SANTOS, M. Por uma outra globalização - Do pensamento único à consciência universal. Rio de J aneiro: Record, 2000.

SANTUR. Municípios de Santa Catarina. 2007. Disponível em: $<$ <ttp//:www.sol.sc.gov.br/ santur/ FrameMunicipios>. Acesso em: 18 nov. 2007.

SETUR.

Cidades/Hidrominerais.

Disponível

em:

$<\mathrm{http} /$ /:www.turismo.rs.gov.br>. Acesso em: 18 nov. 2007

SIMON, H. A. Comportamento administrativo. Rio de J aneiro: Ed. FGV, 1971.

TRIVINOS, A. Introdução à Pesquisa em Ciências Sociais: A Pesquisa Qualitativa em Educação. São Paulo: Atlas, 1987. 